\title{
GESTÃO DA DIVERSIDADE NO BRASIL: ARTIGOS PUBLICADOS NA BASE SPELL NO PERÍODO 2006 - 2016 \\ DIVERSITY MANAGEMENT IN BRAZIL: ARTICLES PUBLISHED IN THE SPELL BASE IN THE PERIOD 2006 - 2016
}

\author{
Eles Calheiros Marques Junior ${ }^{1}$ \\ Ana Luzia de Barros Andrade Marques ${ }^{2}$ \\ Anderson de Barros Dantas 3
}

\section{Resumo}

O objetivo deste trabalho é analisar a produção científica brasileira em gestão da diversidade, publicada na base Spell, no período de 2006 a 2016. Trata-se de uma pesquisa descritiva voltada a indicação das seguintes características: quantitativo dos artigos publicados por ano; identificação dos periódicos e suas respectivas classificações Qualis CAPES; padrão de autoria dos artigos e identificação dos pesquisadores com mais publicações; indicação dos centros geográficos e institucionais difusores da discussão sobre a temática; e apresentação dos eixos da diversidade mais recorrentes nos artigos selecionados, considerando a classificação proposta por Pinheiro e Gois (2013). Os resultados permitem afirmar que a gestão da diversidade apresentou uma produção científica com destacada oscilação anual; que há uma concentração da produção nos estados e instituições do Sudeste e Sul do Brasil; há uma pulverização dos artigos nos periódicos da área de Administração, com média de 1,29 artigos por periódico; e que as publicações analisadas abordaram com mais frequência à diversidade em um contexto geral, seguida pela discussão das dimensões gênero e pessoas com deficiência. Um número reduzido de artigos tratou da diversidade racial e de orientação sexual, e os eixos geracional e imigracional quase não foram contemplados nos artigos sobre gestão da diversidade no Brasil.

Palavras-chave: Gestão da diversidade. Produção científica. Organizações. Eixos da diversidade.

\section{Abstract}

The objective of this work is to analyze the Brazilian scientific production in diversity management, published in the Spell database, from 2006 to 2016. It is a descriptive research, aimed at indicating the

1 Mestre em Administração Pública - PROFIAP/UFAL. Técnico em Assuntos Educacionais do Campus de Engenharias e Ciências Agrárias da Universidade Federal de Alagoas - CECA/UFAL. Maceió, Alagoas, Brasil. E-mail: elesjunior@ hotmail.com

2 Mestra em Educação - CEDU/UFAL. Profess ora da Secretaria de Educação de Alagoas - SEDUC/AL. Maceió, Alagoas, Brasil. E-mail: analuziaanaluzia@gmail.com

3 Doutor em Engenharia de Produção - PPGEP/UFSC. Professor da Faculdade de Economia, Administração e Contabilidade da Universidade Federal de Alagoas-FEAC/UFAL. Maceió, Alagoas, Brasil. E-mail: anderson.dantas@ feac.ufal.br 
following characteristics: quantitative of the published articles per annum; identification of journals and their respective Qualis CAPES; standard of authorship of the articles and identification of the most productive researchers; indication of the geographical and institutional centers that disseminate the discussion on the subject; and presentation of the most recurrent themes of diversity in selected articles, considering the classification proposed by Pinheiro and Gois (2013). The results allow to affirm that the management of diversity presented a scientific production with outstanding annual oscillation; that there is a concentration of production in the states and institutions of the Southeast and South of Brazil; there is a spraying of articles in the periodicals of Administration, with an average of 1.29 articles per period; and that the publications analyzed addressed diversity more frequently in a general context, followed by the discussion of the dimensions of gender and people with disabilities. A limited number of articles dealt with racial diversity and sexual orientation, and the generational and immigration axes were almost ignored in articles on diversity management in Brazil.

Keywords: Diversity management. Scientific production. Organizations. Diversity axes.

\section{INTRODUÇÃO}

A discussão sobre gestão da diversidade no Brasil tem gradativamente ganhado espaço na agenda de pesquisa da ciência administrativa. Com atraso, especialmente se comparado ao estágio da pesquisa sobre a temática em países como Estados Unidos e Canadá, a comunidade acadêmica brasileira da área de Administração tem dedicado atenção ao fenômeno da diversidade no contexto da gestão das organizações.

Esse recente interesse pode ser explicado por diversos fatores, que vão desde a emergência da perspectiva pós-moderna, que ampliou o escopo dos estudos organizacionais ao incorporar temas marginais, como gênero, etnia, tempo, emoções, corpo, estética (CAMPOS; COSTA, 2006); passando pelo impacto das políticas inclusivas efetivadas em subsidiárias brasileiras de empresas estrangeiras, sobretudo dos EUA (PINHEIRO; GOIS, 2013); ou ainda decorrência da ação do governo brasileiro que desde 1995 manifestou interesse em combater à discriminação no mercado de trabalho. (ALVES; GALEÃO-SILVA, 2004).

Além disso, é preciso destacar que a própria atuação legislativa do Estado brasileiro, em resposta aos reclamos da sociedade civil e dos movimentos sociais, demonstra a relevância da problemática da diversidade. Nas últimas décadas foram promulgados diversos dispositivos que tratam da inclusão e garantia de direitos a grupos historicamente marginalizados, como os negros - Lei $\mathrm{n}^{\circ}$ 12.288, de 20/07/2010 (Estatuto da Igualdade Racial), Decreto no 8.136, de 5/11/2013 (regulamenta o Sistema Nacional de Promoção da Igualdade Racial-Sinapir), Lei n ${ }^{\circ} 12.711$, de 29/08/2012 (Lei de Cotas); ou as pessoas com deficiência - Decreto n ${ }^{\circ} 3298$, de 20/12/1999 (regulamenta a Política Nacional para a integração da Pessoa Portadora de Deficiência), Lei 10.098, de 19/12/2000 (promoção da acessibilidade das pessoas portadoras de deficiência ou com mobilidade reduzida), Lei 10.436, de 25/04/2002 (reconhece Libras como meio legal de comunicação e expressão).

No bojo desse processo de "descoberta" da diversidade no Brasil, o presente trabalho objetiva analisar a produção científica sobre gestão da diversidade no período de 2006 a 2016, a partir do mapeamento dos artigos publicados na base de dados Spell. A escolha da década indicada decorreu por considerá-la um 
momento político, social e cultural que representou, no Brasil, uma maior preocupação, defesa e adesão da sociedade, dos governantes e do próprio mundo empresarial a pautas inclusivas e identitárias, com a tentativa de garantir direitos a grupos sociais e minorias historicamente marginalizados. Certamente esse processo tem início antes de 2006. Mas é preciso reconhecer que ganhou fôlego e direcionamento mais propositivo com a ascensão, sobretudo na instância Federal, de governos progressistas, com discurso alinhado a defesa da inclusão social. Já em 2016 tem-se a outra face da moeda: emerge uma onda conservadora no país, que resultou em questionamentos e oposição mais intensa as pautas inclusivas/identitárias. Assim, o período 2006 - 2016 representou, para a pesquisa, um recorte temporal marcado por mudanças sociais e políticas relevantes no cenário nacional, que possivelmente impactaram a diversidade nas organizações e consequentemente as pesquisas acadêmicas sobre a temática.

Constituindo-se em um estudo exploratório-descritivo, tem-se como categorias de análise: indicar o número de artigos publicados por ano; identificar os periódicos e suas respectivas classificações Qualis CAPES; caracterizar o padrão de autoria e identificar os pesquisadores com maior número de publicações; indicar os centros geográficos e institucionais difusores da discussão sobre a temática; e apresentar, de acordo com a proposta de Pinheiro e Gois (2013), os eixos da diversidade mais recorrentes nos artigos sobre gestão da diversidade.

O trabalho estrutura-se, além desta introdução, em quatro partes. A próxima seção aborda o referencial teórico que sustenta a discussão da gestão da diversidade. Nela desenvolve-se a reflexão sobre as origens e o conceito de diversidade, detendo-se na análise de suas dimensões ou eixos. Em seguida é apresentado o procedimento metodológico adotado. Na sequência tem-se a exposição e análise dos resultados, de acordo com cada um dos objetivos específicos estabelecidos. Nas considerações finais tem-se a reafirmação dos objetivos e resultados do estudo, além da indicação de suas limitações e propostas para futuras pesquisas.

\section{REFERENCIAL TEÓRICO}

Inicialmente é preciso contextualizar historicamente a discussão sobre gestão da diversidade. Ela surge, nos Estados Unidos, a partir da década de 1960, com os movimentos políticos favoráveis à integração racial, à igualdade de oportunidades de emprego e educação para todos. De acordo com Cardoso et al. (2007), a gestão da diversidade nasce com a promulgação, na década de 1960, do Affirmative Action nos Estados Unidos.

Gordono (2009, p. 21) assinala que os "governos de Kennedy e Johnson criaram e aprovaram a ação afirmativa através do Civil Right Act, de 2 de julho de 1964, que previa a proibição da discriminação de candidatos aos postos de trabalho oficiais, por raça, religião e nacionalidade". Trata-se de importante conquista dos movimentos organizados e das entidades e lideranças do movimento negro norte-americano que lutavam pelos direitos civis à época, e que tem como exemplo emblemático a atuação de Martin Luther King.

Seguindo o modelo do Affirmative Action, em 1986 no Canadá promulga-se o Employment Equity Act e o Federal Contractors Program, com o objetivo de ampliar o espaço das minorias e promover relações mais justas e equitativas na esfera do trabalho. (FLEURY, 2000).

Todas essas conquistas legais resultaram em mudanças na composição da força de trabalho das organizações. A mão de obra tornou-se mais heterogênea, com diferenças demográficas acentuadas, relativas à idade, gênero, raças, etnias, orientação sexual. E dessa alteração emergem e acentuam-se 
problemas organizacionais, como os relativos à identidade, aceitação, preconceito. Frente a esse novo cenário, a ciência administrativa, especialmente nos EUA e Canadá, voltou-se a discussão sobre a gestão da diversidade nas organizações, sobretudo a partir da década de 1980.

Mas, o que é exatamente diversidade no contexto organizacional? Diversos autores já se dedicaram a refletir sobre esta questão. De forma a sintetizar o debate, reproduz-se no Quadro 1 aspectos relevantes da discussão sobre diversidade nas organizações apresentados nos trabalhos de Gordono (2009) \& Jabbour et al (2011).

Quadro 1- Definições de Diversidade

\begin{tabular}{|l|l|}
\hline \multicolumn{2}{|c|}{ ASPECTOS DA DIVERSIDADE NAS ORGANIZAÇÕES } \\
\hline \multicolumn{1}{|c|}{ Autor(es) } & \multicolumn{1}{c|}{ Definição } \\
\hline Loden \& Rosener (1991) & $\begin{array}{l}\text { A diversidade estabelece a dimensão primária (idade, etnia, gênero, raça, } \\
\text { orientação sexual e habilidades físicas) e a dimensão secundária (formação } \\
\text { educacional, localização geográfica, renda, crença, estado civil e experiência } \\
\text { de trabalho). }\end{array}$ \\
\hline Cox Jr. (1993) & $\begin{array}{l}\text { Gerenciar a diversidade [...] é planejar e executar práticas de gestão de pesso- } \\
\text { as de modo a maximizar as vantagens potenciais da diversidade e minimizar } \\
\text { as suas desvantagens. }\end{array}$ \\
\hline Morrison (1996) & $\begin{array}{l}\text { Não é um modismo, e sim necessidade para a organização se manter compe- } \\
\text { titiva. }\end{array}$ \\
\hline Thomas Jr. (2000) & $\begin{array}{l}\text { As organizações cada vez mais trabalharão com equipes heterogêneas em ter- } \\
\text { mos de raça, etnia, gênero e outros grupos culturalmente diversos. }\end{array}$ \\
\hline Fleury (2000) & $\begin{array}{l}\text { A diversidade torna-se importante e altamente promissora, no sentido de ser } \\
\text { um instrumento de inclusão social. }\end{array}$ \\
\hline
\end{tabular}

Fonte: Gordono (2009) \& Jabbour et al (2011).

A constatação de Morrison (1996) indicada no Quadro 1 sinaliza que a gestão da diversidade não se constitui apenas em algo de base legal, referente à concretização de um direito ou da realização de justiça e inclusão social. É considerada como uma necessidade para a organização manter-se competitiva. Neste aspecto, aproxima-se da visão de Thomas \& Ely (1996), que consideram que uma força de trabalho mais diversificada aumenta a eficácia organizacional, e que a diversidade é boa para os negócios.

Analisada principalmente sob o ponto de vista organizacional, a diversidade pode ser considerada como o atributo que possibilita às organizações atingir, ao mesmo tempo, a compreensão e aproximação aos mercados, e potencializar os bons resultados organizacionais, principalmente no que diz respeito à eficiência dos processos internos. (ARAÚJO, 2012).

As definições de Cox Jr. (1993) \& Fleury (2000) acentuam, respectivamente, a importância de maximizar as vantagens e minimizar as desvantagens da diversidade na organização, e que a gestão da diversidade é um instrumento de inclusão social.

Aproximando-se da definição de Cox Jr. (1993), Cardoso et al destacam que gerir a diversidade

significa considerar as diferenças das pessoas que compõem uma organização, criando uma unidade, de forma a que os vários indivíduos se possam identificar nela, apoiando um sistema organizacional que permita gerir os recursos humanos existentes de modo a maximizar a sua habilidade para perceber e contribuir para a concretização dos objetivos da empresa, atingindo o seu potencial máximo sem haver 
discriminação de sexo, nacionalidade, idade etc. Para atingir este objetivo, deve ser feito um reajuste da cultura organizacional, valores, sistemas e processos de forma a utilizar o capital humano da melhor forma possível. (CARDOSO et al, 2007, p. 6).

As definições de Loden \& Rosener (1991) e Thomas Jr. (2000) acentuam dois aspectos centrais da discussão sobre diversidade. Este assinala que as organizações terão que lidar cada vez mais com a heterogeneidade na força de trabalho. Aqueles tratam das dimensões da diversidade, a partir de dois polos: o da dimensão primária e o da secundária.

Araújo (2012), ao explicar as dimensões primária e secundária da diversidade, ressalta que a primeira se relaciona com atributos objetivos, geralmente biológicos, que se referem às características básicas do indivíduo, como idade, gênero, raça. A dimensão secundária relaciona-se a atributos subjetivos, associados às experiências dos indivíduos, a exemplo da educação, estado civil, origem geográfica, estilos de comunicação, estilo de trabalho ou o papel que desempenha na organização.

Interessante contribuição na perspectiva de aprofundar a discussão sobre a diversidade e suas dimensões é o trabalho de Pinheiro \& Gois (2013). Eles analisaram a diversidade não a partir de suas dimensões, mas por meio do estabelecimento de seis eixos binários, considerados relevantes para o cotidiano das organizações em termos de visibilidade de negócios, marketing e nas políticas de gestão de pessoas. Os eixos sugeridos por Pinheiro \& Gois (2013) foram sintetizados no Quadro 2.

Quadro 2- Eixos da Diversidade

\begin{tabular}{|l|l|}
\hline \multicolumn{1}{|c|}{ Eixo da Diversidade } & \multicolumn{1}{c|}{ Relação Binária } \\
\hline Diversidade Geracional & Jovens x Experientes \\
\hline Diversidade de Gênero & Homens x Mulheres \\
\hline Diversidade Racial & Afrodescendentes x Brancos \\
\hline $\begin{array}{l}\text { Diversidade das Pessoas com Defici- } \\
\text { ência }\end{array}$ & Pessoas com Deficiência x Pessoas que não possuem deficiência \\
\hline Diversidade de Orientação Sexual & Heterossexual x Homossexual \\
\hline Diversidade Imigracional & Trabalhadores nacionais x Trabalhadores expatriados \\
\hline
\end{tabular}

Fonte: Adaptado de Pinheiro \& Gois (2013)

Os eixos da diversidade sugeridos por Pinheiro \& Gois (2013) compreendem especialmente atributos da dimensão primária estabelecidos por Loden \& Rosener (1991). Apenas o eixo imigracional integra a dimensão secundária da diversidade.

Apesar da priorização da dimensão primária, os eixos propostos por Pinheiro \& Gois (2013) serão a base para análise dos artigos publicados no Brasil a respeito da gestão da diversidade. Tal opção deriva da aceitação que os problemas relativos à gestão da diversidade no país ocorrem principalmente em relação aos seis eixos citados, não de forma exclusiva, mas com uma maior recorrência quando comparado a outras dimensões, como a relativa a estilos de comunicação ou estilo de trabalho.

Outra ressalva a ser feita diz respeito especificamente a relação binária estabelecida pelos autores. Trata-se de um reducionismo, que acaba por não considerar, em cada eixo ou dimensão, questões explícitas ou implícitas que perpassam o debate sobre diversidade no Brasil. Por exemplo, restringir o eixo racial a uma relação binária entre afrodescendentes x brancos, acaba por desconsiderar, invisibilizar outros grupos, como os indígenas. Mas mesmo cientes deste reducionismo, que também 
se reflete na consideração da diversidade de gênero como uma questão relacionada exclusivamente ao sexo biológico, a uma relação binária entre homens x mulheres, considerou-se que a proposta de Pinheiro \& Gois (2013) possibilita uma interessante classificação exploratória dos estudos sobre diversidade nas organizações brasileiras.

A diversidade é um conceito multidimensional, "que abrange diferenças individuais étnico-racial, de gênero, orientação sexual, da geração, da classe social, das capacidades físicas e mentais, da família, da religião, regional, profissional, político e de outras afiliações pessoais." (MACCALI et al, 2015). Gerir a diversidade é exatamente gerir essas diferenças, em proveito das organizações e especialmente das pessoas. Baseia-se na aceitação das diferenças existentes entre os indivíduos e no tratamento delas como um potencial a ser desenvolvido. (MACCALI et al, 2015). Certamente não é uma tarefa fácil, pois envolve rever estruturas de poder, hábitos, comportamentos no ambiente de trabalho, mas que se constitui em elemento central para a competitividade e a criação de valor nas organizações contemporâneas.

\section{METODOLOGIA}

Para o atendimento do objetivo do trabalho, realizou-se pesquisa descritiva, com utilização dos procedimentos da pesquisa bibliográfica e revisão sistemática de literatura para analisar a produção científica brasileira que trata da gestão da diversidade.

O levantamento dos artigos foi realizado na base de dados Spell. De acordo com Costa \& Gomes (2017, p. 1) o "Spell - Scientific Periodicals Electronic Libraryé um portal brasileiro que envolve um sistema de indexação, pesquisa e disponibilização gratuita da produção científico-profissional nas áreas de Administração, Contabilidade e Turismo". Sendo uma iniciativa da Associação Nacional de Pós-Graduação e Pesquisa em Administração - ANPAD, a base Spell constitui um importante repositório de artigos científicos da área das ciências sociais aplicadas.

O recenseamento dos artigos na base Spell foi realizado na primeira quinzena de setembro de 2017. Utilizando-se da palavra-chave "Gestão da Diversidade", sem indicação de campo específico, com filtro temporal de janeiro de 2006 a dezembro de 2016, a busca na base Spell resultou em 130 artigos. Cada um foi analisado inicialmente a partir do título, palavras-chave e resumo, com a finalidade de selecionar apenas aqueles que tivessem relação direta com a discussão sobre gestão da diversidade em qualquer uma de suas dimensões ou eixos - gênero, raça, orientação sexual, pessoas com deficiência, geracional e imigracional.

Com a triagem, identificou-se 44 artigos que se relacionavam diretamente a gestão da diversidade. Eles constituem as unidades de análise desta pesquisa.

Selecionados os artigos, foi realizada a tabulação dos dados. Para tanto, utilizou-se o programa Microsoft Excel, versão 2010, e a partir dele foram construídas as tabelas e gráficos para análise e discussão dos resultados. As informações extraídas de cada um dos artigos, necessárias a análise da produção científica sobre gestão da diversidade, foram às seguintes: a) Ano da Publicação; b) Autor(es); c) Periódico e seu respectivo Qualis CAPES; d) Instituição vínculo do(s) autor(es); e) Unidade da Federação (UF) de atuação acadêmico-profissional do(s) autor(es); f) Título do Artigo;

g) Palavras-chave; h) Objetivos; i) Metodologia; j) Conclusões; e k) Referência do artigo no padrão ABNT e APA. 
Com os dados tabulados, foi possível examinar os seguintes aspectos, tomados como categorias de análise do trabalho: avaliar o quantitativo de artigos publicados, por ano, no período de 2006 a 2016; identificar o padrão de autoria dos artigos e os pesquisadores com maior número de publicações; destacar os periódicos com mais publicações sobre gestão da diversidade, com a indicação de seus respectivos Qualis CAPES; apresentar os centros geográficos e institucionais que mais contribuíram na discussão da temática; e identificar, considerando a classificação proposta por Pinheiro \& Gois (2013), os eixos da diversidade mais recorrentes nos artigos selecionados. Neste último aspecto, para ilustrar os tópicos nucleares da discussão sobre gestão da diversidade, foi elaborada nuvem de palavras, gerada por meio do software Wordle.net, a partir das palavras-chave presentes nos artigos.

É preciso ainda ressaltar a concepção filosófica que orientou a feitura desta pesquisa. À primeira vista, parece ser um trabalho de cunho pós-positivista, nos termos de Creswell (2010), por utilizar-se de uma abordagem descritiva. Mas o que o motivou, o que norteou a escolha do tema e o interesse em discutir a questão da diversidade nas organizações, funda-se em uma posição reivindicatória, em um olhar sobre o problema lançado a partir de uma concepção reivindicatória/participatória. (CRESWELL, 2010). Tal demarcação se faz necessária, porque mesmo sendo descritivo, com o objetivo de analisar demograficamente aspectos da produção acadêmica sobre gestão da diversidade, este trabalho se funda em uma visão emancipatória, comprometida com uma agenda social e política que atenta para as necessidades dos grupos e dos indivíduos socialmente marginalizados ou privados de direitos. (CRESWELL, 2010). Este trabalho se alinha ainda a perspectiva pós-moderna, que ampliou o escopo dos estudos organizacionais ao incorporar temas antes considerados marginais, como gênero, etnia, tempo, emoções, corpo, estética. (CAMPOS; COSTA, 2006).

Dessa forma, a análise da produção acadêmica sobre gestão da diversidade visa compreender como esta temática tem sido abordada pela Administração na última década, na expectativa de construir um retrato, mesmo que parcial, da gestão da diversidade no Brasil.

\section{ANÁLISE DOS RESULTADOS}

Nesta seção, apresentam-se os resultados da pesquisa, com a análise e discussão dos seguintes aspectos: 1) Distribuição dos artigos sobre gestão da diversidade no período 2006-2016; 2) Quantidade de autores por artigo e os pesquisadores com mais publicações; 3) Quantidade de artigos por periódico; 4) Centros geográficos e institucionais difusores da discussão sobre gestão da diversidade; e 5) Eixos mais recorrentes da gestão da diversidade.

\subsection{Distribuição dos artigos sobre Gestão da Diversidade no período 2006-2016}

$\mathrm{O}$ primeiro aspecto a ser analisado se refere à quantidade de artigos publicados, por ano, no período de 2006 a 2016. O Gráfico 1 apresenta essa distribuição. 
Gráfico 1- Artigos sobre Gestão da Diversidade publicados, por ano, no período 2006-2016

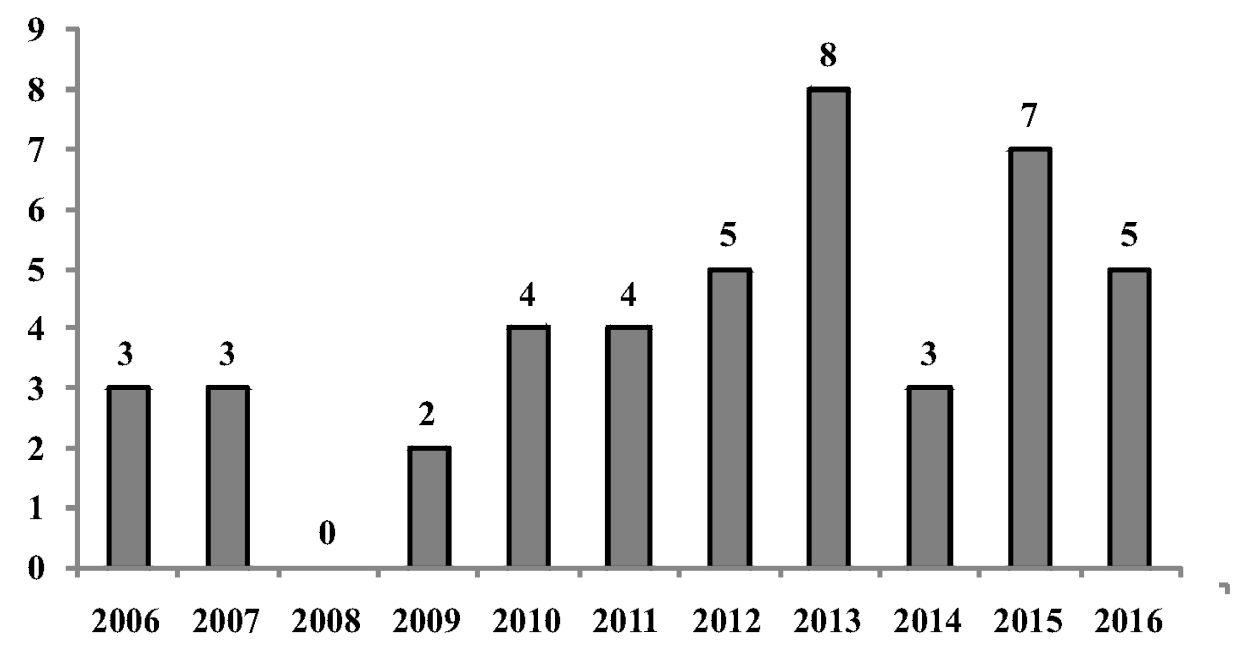

Fonte: Organizada pelos autores, segundo dados da pesquisa, 2017.

A distribuição dos 44 artigos sobre gestão da diversidade coletados na base Spell demonstra uma pronunciada oscilação no número de publicações por ano, o que inviabiliza determinar se há uma tendência de acréscimo ou decréscimo na produção sobre a temática. Por meio da Figura 3 confirma-se que não tem ocorrido um crescimento linear na produção científica sobre gestão da diversidade no Brasil. Há anos com produção mais expressiva, como 2013 e 2015; e no oposto a ausência de publicação, como ocorrido em 2008. O que marca a produção científica no período é a oscilação no número de publicações. Mesmo ao considerar o quantitativo de artigos publicados após 2011 como mais expressivo do que o que foi produzido nos cinco anos anteriores - de 2012 a 2016 tem-se 28 artigos, contra 12 no período 2006-2010, não é seguro afirmar que isto represente uma tendência consistente de crescimento e/ou consolidação da temática nos estudos administrativos.

Não há, a considerar o quantitativo da produção científica sobre gestão da diversidade no período de 2006 a 2016, um crescimento linear das publicações. Ao contrário, o que se evidencia é a inconstância desta produção.

\subsection{Quantidade de autores por artigo e pesquisadores com mais publicações}

O padrão de autoria dos 44 artigos selecionados é o próximo aspecto a ser avaliado. A Tabela1apresenta a quantidade de autores por artigo.

Tabela 1 - Quantidade de autores por artigo

\begin{tabular}{|c|c|c|c|c|c|c|c|c|c|c|c|c|c|}
\hline \multirow{2}{*}{$\begin{array}{c}\mathbf{N}^{0} \text { de } \\
\text { Autores }\end{array}$} & \multicolumn{11}{|c|}{ Ano } & \multirow{2}{*}{ Total } & \multirow{2}{*}{$\%$} \\
\hline & 2006 & 2007 & 2008 & 2009 & 2010 & 2011 & 2012 & 2013 & 2014 & 2015 & 2016 & & \\
\hline 1 Autor & 1 & 0 & 0 & 0 & 1 & 1 & 0 & 1 & 2 & 2 & 1 & 9 & $20 \%$ \\
\hline 2 Autores & 2 & 1 & $\overline{0}$ & 1 & 2 & 2 & 3 & 2 & 0 & 1 & 1 & 15 & $34 \%$ \\
\hline 3 Autores & 0 & 0 & 0 & 1 & 0 & 1 & 1 & 3 & 0 & 2 & 2 & 10 & $23 \%$ \\
\hline 4 Autores & 0 & 1 & 0 & 0 & 0 & 0 & 0 & 1 & 0 & 1 & 1 & 4 & $9 \%$ \\
\hline Mais de 4 & 0 & 1 & 0 & 0 & 1 & 0 & 1 & 1 & 1 & 1 & 0 & 6 & $14 \%$ \\
\hline Total & 3 & 3 & 0 & 2 & 4 & 4 & 5 & 8 & 3 & 7 & 5 & 44 & $100 \%$ \\
\hline
\end{tabular}

Fonte: Organizada pelos autores, segundo dados da pesquisa, 2017. 
Há prevalência de trabalhos com dois autores (34\%). No oposto, as publicações com quatro autores apresentaram a menor frequência, $9 \%$ dos trabalhos publicados no período.

Evidencia-se a prática da parceria na produção científica, com $80 \%$ dos artigos sendo escritos por dois ou mais autores. Em especial destacam-se as publicações com dois autores, o que configura a provável parceria entre orientador e orientando, ou professor e aluno, ou ainda o resultado de trabalhos originários de dissertações de mestrado ou teses de doutorado, como já assinalado por Gomes, Lavarda \& Torrens (2012) e Gomes et al (2014).

Também é relevante identificar os pesquisadores com mais publicações. A Tabela 2 apresenta os autores que publicaram mais de um artigo no período.

Tabela 2 - Pesquisadores com mais publicações

\begin{tabular}{|l|c|c|c|}
\hline \multicolumn{1}{|c|}{ Pesquisador(a) } & Instituição & UF & $\begin{array}{c}\mathbf{N}^{\mathbf{0}} \text { de } \\
\text { artigos }\end{array}$ \\
\hline Jamille Barbosa Cavalcanti Pereira & Universidade Presbiteriana Mackenzie & SP & 4 \\
\hline Maria Nivalda de Carvalho-Freitas & Universidade Federal de São João Del-Rei & MG & 3 \\
\hline Marlene Catarina de Oliveira Lopes Melo & Faculdade Novos Horizontes & MG & 2 \\
\hline Tereza Cristina Batista de Lima & Universidade Federal do Ceará & CE & 2 \\
\hline João Luís Alves Pinheiro & Universidade Federal Rural do Rio de & \multirow{2}{*}{ RJ } & 2 \\
\hline João Bosco Hora Gois & Universidade Federal Fluminense & RJ & 2 \\
\hline Antônio Luiz Marques & Universidade Federal de Minas Gerais & MG & 2 \\
\hline
\end{tabular}

Fonte: Organizada pelos autores, segundo dados da pesquisa, 2017.

Dos 107 pesquisadores que contribuíram com artigos sobre gestão da diversidade, apenas sete tiveram mais de um artigo publicado no período na base Spell. Dos pesquisadores indicados na Tabela 2, apenas um não atua na região Sudeste, Tereza Cristina Batista de Lima, que publicou dois artigos e está vinculada a Universidade Federal do Ceará.

Mas em termos de publicações, duas pesquisadoras se destacaram: as professoras Jamille Barbosa Cavalcanti Pereira (quatro publicações) e Maria Nivalda de Carvalho-Freitas (três artigos), vinculadas, respectivamente, a Universidade Presbiteriana Mackenzie e a Universidade Federal de São João Del-Rei. Uma coincidência verificada ao consultar o currículo Lattes das autoras é que ambas possuem formação em nível de graduação na área de Psicologia, com doutoramento em Administração. Há possibilidade de que a formação inicial das autoras tenha contribuído na escolha da temática diversidade.

\subsection{Quantidade de artigos por periódico de 2006 a 2016}

A indicação dos periódicos em que os artigos foram publicados constitui-se em informação relevante para avaliar o impacto da produção sobre gestão da diversidade, especialmente a partir da consideração do Qualis Capes, e se há um veículo que concentra as publicações sobre a temática. A Tabela 3 apresenta essa distribuição.

Os 44 artigos selecionados na base Spell foram publicados em 34 periódicos distintos, dentre eles alguns de alto impacto, classificados pela CAPES no estrato A2, como as revistas O\&S, RAC, RAE e RBGN. Os periódicos com maior número de publicações foram a RECAPE e a RIGS, ambas classificadas pela CAPES como B4, e cada uma com três artigos publicados sobre gestão da diversi- 
dade no período 2006 - 2016. Outros seis periódicos publicaram dois trabalhos, e os demais apenas um artigo no período considerado.

O que se constata é que a produção científica em gestão da diversidade não possui um veículo próprio para divulgação dos trabalhos realizados. Ainda não se constituiu um periódico voltado prioritariamente à discussão da diversidade nas organizações, e em consequência as pesquisas produzidas acabam por se espraiar em revistas que cobrem desde a área contábil a um e outro campo restrito da administração. O que explica em parte ter-se 44 artigos publicados em 34 periódicos distintos, uma média de 1,29 artigos por periódico.

Tabela 3 - Quantidade de artigos por periódico

\begin{tabular}{|c|c|c|c|c|}
\hline Periódico & ISSN & $\begin{array}{c}\text { Qualis } \\
\text { CAPES }\end{array}$ & $\begin{array}{l}\text { Quant. } \\
\text { Artigos }\end{array}$ & $\%$ \\
\hline RECAPE - Revista de Carreiras e Pessoas & $2237-1427$ & B4 & 3 & $7 \%$ \\
\hline RIGS - Revista Interdisciplinar de Gestão Social & $2317-2428$ & B4 & 3 & $7 \%$ \\
\hline Gestão \& Conexões & $2317-5087$ & B4 & 2 & $5 \%$ \\
\hline GESTÃO.Org - Revista Eletrônica de Gestão Organizacional & $1679-1827$ & B3 & 2 & $5 \%$ \\
\hline O\&S - Organizações \& Sociedade & $1984-9230$ & $\mathrm{~A} 2$ & 2 & $5 \%$ \\
\hline RAC - Revista de Administração Contemporânea & $1982-7849$ & $\mathrm{~A} 2$ & 2 & $5 \%$ \\
\hline RBGN - Revista Brasileira de Gestão de Negócios & $1806-4892$ & $\mathrm{~A} 2$ & 2 & $5 \%$ \\
\hline Revista Pensamento Contemporâneo em Administração & $1982-2596$ & $\mathrm{~B} 2$ & 2 & $5 \%$ \\
\hline Cadernos EBAPE.BR & $1679-3951$ & $\mathrm{~A} 2$ & 1 & $2 \%$ \\
\hline CGPC - Cadernos Gestão Pública e Cidadania & $2236-5710$ & $\mathrm{~B} 1$ & 1 & $2 \%$ \\
\hline Contextus - Revista Contemporânea de Economia e Gestão & $2178-9258$ & $\mathrm{~B} 2$ & 1 & $2 \%$ \\
\hline E\&G - Revista Economia \& Gestão & $1984-6606$ & $\mathrm{~B} 2$ & 1 & $2 \%$ \\
\hline Enfoque Reflexão Contábil & 1984-882X & B1 & 1 & $2 \%$ \\
\hline G\&P - Revista Gestão \& Planejamento & $2178-8030$ & B2 & 1 & $2 \%$ \\
\hline GeP - Revista de Gestão e Projetos & $2236-0972$ & B3 & 1 & $2 \%$ \\
\hline Gesec - Revista de Gestão e Secretariado & $2178-9010$ & $\mathrm{~B} 2$ & 1 & $2 \%$ \\
\hline Gestão \& Regionalidade & $2176-5308$ & B2 & 1 & $2 \%$ \\
\hline Pensamento \& Realidade & $2237-4418$ & B3 & 1 & $2 \%$ \\
\hline Pensar Contábil & $1519-0412$ & $\mathrm{~B} 2$ & 1 & $2 \%$ \\
\hline RAE - Revista de Administração de Empresas & $0034-7590$ & $\mathrm{~A} 2$ & 1 & $2 \%$ \\
\hline RAE-eletrônica & $1676-5648$ & $\mathrm{~A} 2$ & 1 & $2 \%$ \\
\hline RAM - Revista de Administração Mackenzie & $1678-6971$ & $\mathrm{~B} 1$ & 1 & $2 \%$ \\
\hline RAU - Revista de Administração da Unimep & $1679-5350$ & $\mathrm{~B} 2$ & 1 & $2 \%$ \\
\hline RAUSP - Revista de Administração & 0080-2107 & $\mathrm{A} 2$ & 1 & $2 \%$ \\
\hline RCCe - Revista Capital Científico - Eletrônica & $1679-1991$ & B3 & 1 & $2 \%$ \\
\hline ReA UFSM - Revista de Administração da UFSM & $1983-4659$ & $\mathrm{~B} 2$ & 1 & $2 \%$ \\
\hline REGE - Revista de Gestão & $2177-8736$ & $\mathrm{~B} 1$ & 1 & $2 \%$ \\
\hline Revista ADM.MADE & $1518-9929$ & $\mathrm{~B} 2$ & 1 & $2 \%$ \\
\hline Revista Gestão \& Tecnologia & $1677-9479$ & B3 & 1 & $2 \%$ \\
\hline Revista Sociedade, Contabilidade e Gestão & $1982-7342$ & B2 & 1 & $2 \%$ \\
\hline RGO - Revista Gestão Organizacional & $1983-6635$ & B4 & 1 & $2 \%$ \\
\hline ROC - Revista Organizações em Contexto & $1982-8756$ & $\mathrm{~B} 1$ & 1 & $2 \%$ \\
\hline RTVA - Turismo: Visão e Ação & $1415-6393$ & $\mathrm{~B} 1$ & 1 & $2 \%$ \\
\hline TPA - Teoria e Prática em Administração & $2238-104 X$ & $\mathrm{~B} 2$ & 1 & $2 \%$ \\
\hline Total & - & - & 44 & $100 \%$ \\
\hline
\end{tabular}

Fonte: Organizada pelos autores, segundo dados da pesquisa, 2017. 
O impacto da produção sobre gestão da diversidade pode ser avaliado a partir dos periódicos em que os artigos são publicados. Neste sentido, é relevante detalhar a distribuição dos artigos em relação ao Qualis CAPES.

Evidencia-se que $77 \%$ dos artigos foram publicados em periódicos classificados pela CAPES no estrato B. Destes, destacam-se os veiculados em periódicos B2, com 13 artigos, a corresponder aproximadamente $30 \%$ do total de trabalhos publicados no período. A base de dados Spell não identificou nenhum trabalho publicado em periódico classificado no estrato A1. Mas em relação ao estrato A2 tem-se 10 artigos, ou $23 \%$ dos trabalhos publicados no período. Este último dado é revelador da qualidade dos trabalhos publicados sobre gestão da diversidade.

\subsection{Centros geográficos e institucionais difusores da Gestão da Diversidade}

Para identificar os centros geográficos e institucionais difusores da gestão da diversidade, considerou-se o número de pesquisadores e trabalhos publicados por região geográfica. Dessa forma, é apresentado na Tabela 4 o quantitativo dos autores por instituição de vínculo indicada no artigo, pois a intenção foi apresentar a filiação institucional do pesquisador no momento da publicação do trabalho. Apenas uma autora não indicou com precisão a instituição da qual fazia parte. Trata-se de Patrícia Araújo Henderson, autora do artigo "As barreiras para a ascensão da mulher a posições hierárquicas: um estudo sob a óptica da gestão da diversidade no Brasil." (HENDERSON; FERREIRA; DUTRA, 2016).

A maior parte dos artigos que tratam da gestão da diversidade foram elaborados por autores que atuam em estados do Sudeste e Sul do Brasil. Consequentemente, as instituições localizadas nestas regiões são os centros difusores do debate sobre gestão da diversidade no país. A Tabela 4 demonstra a centralidade de estados como São Paulo, Rio de Janeiro, Minas Gerais, Paraná, e de instituições como a Universidade Presbiteriana Mackenzie, Universidade de São Paulo, Universidade Federal de Minas Gerais, Universidade Federal Fluminense, Universidade Federal do Paraná, dentre outros centros de ensino e pesquisa das duas regiões, na promoção da discussão sobre a diversidade nas organizações brasileiras.

Aproximadamente $86,79 \%$ dos pesquisadores que publicaram artigos sobre gestão da diversidade são filiados as instituições de pesquisa do Sudeste (70,75\% dos autores) e Sul (16,04\%). As regiões Centro-Oeste (três autores) e Norte (um autor) tiveram baixa representatividade no total de pesquisadores dedicados a discussão da diversidade organizacional. Na região Nordeste, com nove pesquisadores vinculados a três instituições universitárias, destacou-se a Universidade Federal do Ceará, com seis pesquisadores dedicando-se a gestão da diversidade. 
Tabela 4 - Quantidade de autores por Instituição e Região Geográfica

\begin{tabular}{|c|c|c|c|}
\hline Região & Instituição & $\mathbf{U F}$ & $\begin{array}{l}\mathrm{N}^{0} \text { de Autores } \\
\text { por Instituição }\end{array}$ \\
\hline \multirow{3}{*}{ Centro-Oeste } & Universidade de Brasília (UNB) & $\mathrm{DF}$ & 2 \\
\hline & Universidade Federal do Mato Grosso do Sul (UFMS) & MS & 1 \\
\hline & Total Centro-Oeste & - & 3 \\
\hline \multirow{4}{*}{ Nordeste } & Universidade Federal do Ceará (UFC) & $\mathrm{CE}$ & 6 \\
\hline & Universidade de Fortaleza (UNIFOR) & $\mathrm{CE}$ & 2 \\
\hline & Universidade Federal do Piauí & PI & 2 \\
\hline & Total Nordeste & - & 10 \\
\hline \multirow{2}{*}{ Norte } & Universidade Federal do Amapá (UNIFAP) & $\mathrm{AP}$ & 1 \\
\hline & Total Norte & - & 1 \\
\hline \multirow{25}{*}{ Sudeste } & Universidade Presbiteriana Mackenzie & SP & 19 \\
\hline & Universidade de São Paulo (USP) & $\mathrm{SP}$ & 8 \\
\hline & Universidade Federal Fluminense (UFF) & $\mathrm{RJ}$ & 7 \\
\hline & Universidade Federal de Minas Gerais (UFMG) & MG & 6 \\
\hline & Universidade Federal de São João del-Rei (UFSJ) & MG & 4 \\
\hline & Fundação Getulio Vargas (EBAPE/FGV) & $\mathrm{RJ}$ & 4 \\
\hline & Universidade do Grande Rio (UNIGRANRIO) & RJ & 3 \\
\hline & Faculdade Novos Horizontes & MG & 2 \\
\hline & Universidade Federal Rural do Rio de Janeiro (UFRRJ) & RJ & 2 \\
\hline & Fundação Getúlio Vargas (EAESP/FGV) & $\mathrm{SP}$ & 2 \\
\hline & Pontifícia Universidade Católica do Rio de Janeiro (PUC/RJ) & $\mathrm{RJ}$ & 2 \\
\hline & Universidade do Estado do Rio de Janeiro (UERJ) & $\mathrm{RJ}$ & 2 \\
\hline & Universidade Federal de Lavras (UFLA) & MG & 2 \\
\hline & Universidade Federal do Rio de Janeiro (UFRJ) & $\mathrm{RJ}$ & 2 \\
\hline & $\begin{array}{l}\text { Associação de Pais e Amigos dos Excepcionais de Belo Horizonte } \\
\text { (Apae-BH) }\end{array}$ & MG & 1 \\
\hline & Escola Superior de Propaganda e Marketing (ESPM) & $\mathrm{SP}$ & 1 \\
\hline & Federação das Apaes do Estado de Minas Gerais & MG & 1 \\
\hline & Insper Instituto de Ensino e Pesquisa & $\mathrm{SP}$ & 1 \\
\hline & Santander Asset Management & SP & 1 \\
\hline & Universidade Estácio de Sá & $\mathrm{RJ}$ & 1 \\
\hline & Universidade Estadual Paulista (UNESP) & $\mathrm{SP}$ & 1 \\
\hline & Universidade Federal de Viçosa (UFV) & MG & 1 \\
\hline & Universidade Federal do Espírito Santo (UFES) & ES & 1 \\
\hline & Universidade Salgado de Oliveira (UNIVERSO) & $\mathrm{RJ}$ & 1 \\
\hline & Total Sudeste & - & 75 \\
\hline \multirow{8}{*}{ Sul } & Universidade Federal do Paraná (UFPR) & $\mathrm{PR}$ & 7 \\
\hline & Universidade Federal de Santa Catarina (UFSC) & $\mathrm{SC}$ & 3 \\
\hline & Universidade Estadual de Maringá (UEM) & $\mathrm{PR}$ & 2 \\
\hline & Universidade Estadual do Centro Oeste (UNICENTRO) & PR & 2 \\
\hline & Faculdade Integrada de Santa Maria (FISMA) & $\mathrm{RS}$ & 1 \\
\hline & Instituição Educacional São Judas Tadeu (IESJT) & $\mathrm{RS}$ & 1 \\
\hline & Universidade Federal do Rio Grande do Sul (UFRGS) & $\mathrm{RS}$ & 1 \\
\hline & Total Sul & - & 17 \\
\hline Brasil & Total & BR & 106 \\
\hline
\end{tabular}

Fonte: Organizada pelos autores, segundo dados da pesquisa, 2017. 
Ainda a partir da Tabela 4 constata-se o papel de destaque da Universidade Presbiteriana Mackenzie, com 19 pesquisadores associados. Contabilizados especificamente os artigos publicados por pesquisadores vinculados a instituição, tem-se sete publicações. Destas, quatro contam com a participação da professora Jamille Barbosa Cavalcanti Pereira, a pesquisadora mais produtiva no período 2006-2016. Dessa forma, corrobora-se a importância da Universidade Presbiteriana Mackenzie e de seus pesquisadores na reflexão sobre gestão da diversidade.

A Tabela 5 apresenta o quantitativo de instituições, pesquisadores e artigos por região. Em relação aos últimos, é preciso assinalar que algumas publicações foram contabilizadas em mais de uma região, pois representam a parceria entre autores que atuam em instituições sediadas em regiões geográficas distintas. Por exemplo, o artigo "As representações sociais de secretários executivos gays: questões de gênero e diversidade no trabalho." (SOUZA; MARTINS; SOUZA, 2015), de autoria dos pesquisadores Eduardo Cesar Pereira Souza (Universidade Federal do Amapá), Cibele Barsalini Martins (Universidade Federal de Santa Catarina) e Rosália Beber de Souza (Universidade Federal de Viçosa) foi computado como publicação para as regiões Norte, Sul e Sudeste, respectivamente. Da mesma forma, os artigos "Gestão da diversidade: um estudo de gênero e raça em grandes empresas brasileiras.” (GONÇALVES; ESPEJO; ALTOÉ; VOESE, 2016), e "Mulheres e Valores do Trabalho: Estudo em uma Multinacional." (BRANDÃO; FERRAZ; LIMA, 2015), foram computados para mais de uma região. O primeiro para as regiões Centro-Oeste e Sul; e o segundo considerado para as regiões Nordeste e Sudeste. Os 41 artigos restantes foram classificados em apenas uma região. Assim, tomando como referência a Tabela 5, o total de artigos (somatório das cinco regiões) resulta em 48 publicações. A divergência com o número de artigos selecionados na base Spell (44) decorre da consideração dos três artigos mencionados em mais de uma região geográfica.

Tabela 5 - Gestão da Diversidade: quantitativo de Instituições, Pesquisadores e Artigos por Região Geográfica

\begin{tabular}{|l|c|c|c|c|c|c|}
\hline \multirow{2}{*}{ Região Geográfica } & \multicolumn{2}{|c|}{ Instituições } & \multicolumn{2}{c|}{ Pesquisadores } & \multicolumn{2}{c|}{ Artigos } \\
\cline { 2 - 7 } & Frequência & $\%$ & Frequência & $\%$ & Frequência & $\%$ \\
\hline Centro-Oeste & 2 & $5 \%$ & 3 & $3 \%$ & 2 & $4 \%$ \\
\hline Nordeste & 3 & $8 \%$ & 10 & $9 \%$ & 4 & $8 \%$ \\
\hline Norte & 1 & $3 \%$ & 1 & $1 \%$ & 1 & $2 \%$ \\
\hline Sudeste & 24 & $65 \%$ & 75 & $71 \%$ & 34 & $71 \%$ \\
\hline Sul & 7 & $19 \%$ & 17 & $16 \%$ & 7 & $15 \%$ \\
\hline Total & $\mathbf{3 7}$ & $100 \%$ & $\mathbf{1 0 6}$ & $100 \%$ & $\mathbf{4 8}$ & $100 \%$ \\
\hline
\end{tabular}

Fonte: Organizada pelos autores, segundo dados da pesquisa, 2017.

Com a Tabela 5 confirma-se a primazia da região Sudeste na discussão sobre gestão da diversidade, respondendo por $71 \%$ dos artigos publicados na base Spell no período de 2006 a 2016 . Tomada em conjunto com a região Sul, tem-se $86 \%$ das publicações, $87 \%$ dos pesquisadores e $84 \%$ das instituições. Evidencia-se, ainda, a situação de atraso na pesquisa sobre gestão da diversidade nas regiões Norte, Centro-Oeste e Nordeste, que juntas responderam apenas por $13 \%$ dos pesquisadores, $16 \%$ das instituições e $14 \%$ dos artigos publicados sobre diversidade nas organizações no período considerado. 


\subsection{Eixos recorrentes na discussão sobre Gestão da Diversidade}

A gestão da diversidade não se restringe a discussão sobre gênero ou raça. (MACCALI et al, 2015; ARAÚJO, 2012). Ela é mais ampla, compreende uma gama variada de temas emergentes, relacionados aos direitos das minorias historicamente subalternizadas, dos excluídos dos postos de trabalho qualificados, daqueles impedidos de ascender ao alto escalão das empresas, dos homens e mulheres a quem foi/é negado o direito de ocupar empregos/funções de maior prestígio econômico e social.

A gestão da diversidade considerada compreende principalmente os eixos propostos por Pinheiro \& Gois (2013). Trata-se de uma concepção que abarca a questão geracional, racial, de gênero, imigracional, das pessoas com deficiência e da diversidade de orientação sexual.

O que se espera, ao avaliar os tópicos mais recorrentes nos artigos selecionados, é identificar quais eixos da diversidade sobressaíram na produção científica brasileira. A Tabela 6 apresenta a distribuição dos artigos a partir dos eixos da diversidade.

Tabela 6- Distribuição dos artigos nos eixos da diversidade propostos por Pinheiro \& Gois (2013)

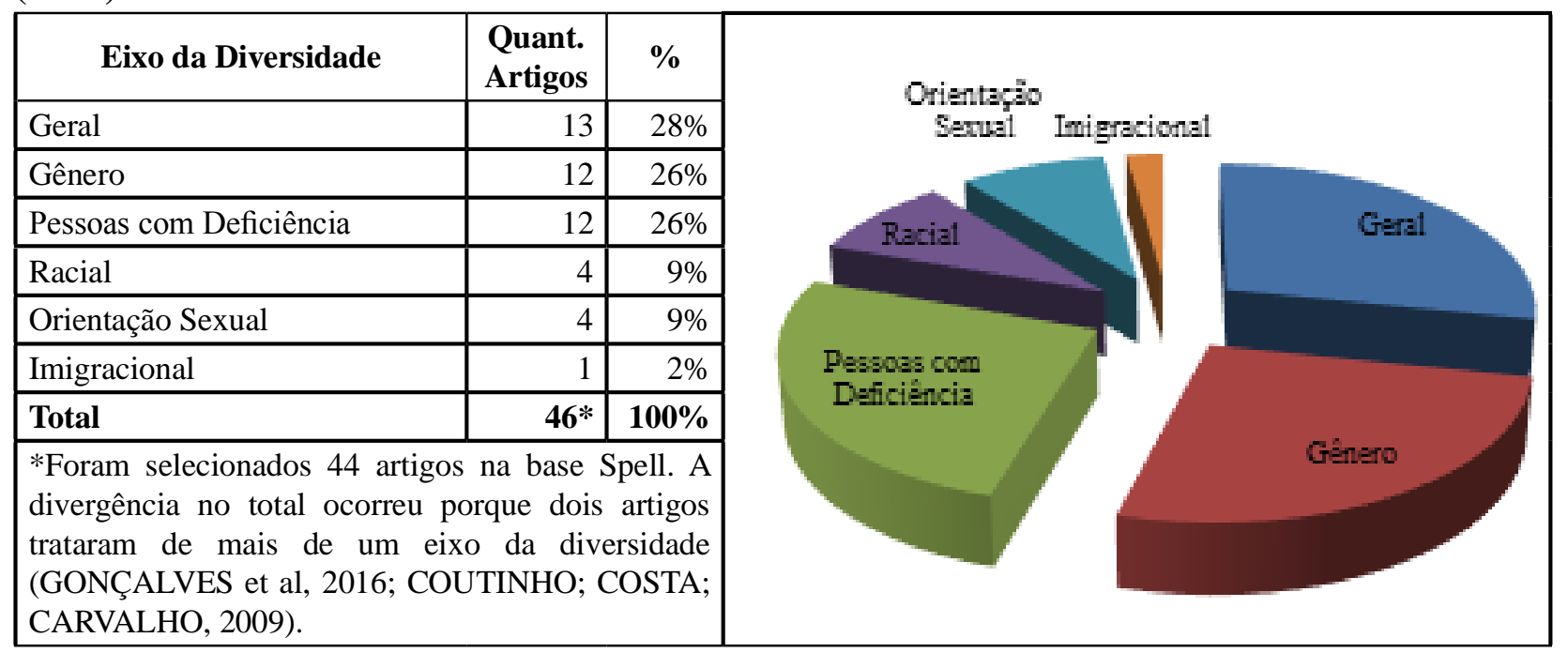

Fonte: Organizada pelos autores, segundo dados da pesquisa, 2017.

Foram identificados 13 artigos de abordagem geral sobre a gestão da diversidade. Ou seja, artigos que trataram da diversidade nas organizações de maneira abrangente, não a partir de um eixo ou dimensão específica dentre as seis propostas por Pinheiro \& Gois (2013). Os eixos que mais sobressaíram foram os de gênero e pessoas com deficiência, cada um com 12 artigos.

É preciso destacar que dois artigos abordaram mais de um eixo da diversidade. Trata-se das publicações "Gestão da diversidade: um estudo de gênero e raça em grandes empresas brasileiras." (GONÇALVES et al, 2016) e "Debatendo diversidade de gênero e raça no contexto organizacional brasileiro: lei do mercado ou cotas por lei? (COUTINHO; COSTA; CARVALHO, 2009). Coincidentemente, ambos artigos abordaram os eixos gênero e racial.

Os eixos da diversidade racial e de orientação sexual foram contemplados, cada um, com quatro artigos. Em relação especificamente a dimensão racial, permanece a situação identificada por Costa \& Ferreira (2006), de que os temas raça e etnia são praticamente inexplorados nos estudos organizacionais. 
A ausência foi o eixo geracional, não abordado de forma exclusiva ou prioritária em nenhum dos artigos consultados. O eixo imigracional também tem sido relegado nas pesquisas sobre gestão da diversidade, com apenas um artigo a se debruçar mais detidamente sobre a temática. O Quadro 3 identifica cada um dos artigos classificados por eixo da diversidade.

Quadro 3- Indicação dos artigos por eixos da diversidade de Pinheiro \& Gois (2013)

\begin{tabular}{|c|c|c|}
\hline Eixo & Artigo & Citação \\
\hline \multirow{12}{*}{ 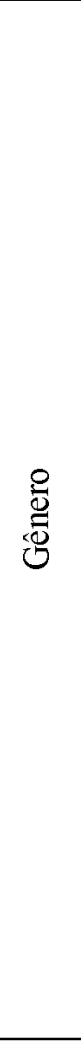 } & $\begin{array}{l}\text { As Barreiras para a Ascensão da Mulher a Posições Hierárquicas: um } \\
\text { Estudo sob a Óptica da Gestão da Diversidade No Brasil }\end{array}$ & $\begin{array}{l}\text { HENDERSON; FERREIRA; } \\
\text { DUTRA, } 2016 .\end{array}$ \\
\hline & $\begin{array}{l}\text { Gestão da diversidade: um estudo de gênero e raça em grandes empresas } \\
\text { brasileiras }\end{array}$ & $\begin{array}{l}\text { GONÇALVES; ESPEJO; } \\
\text { ALTOÉ; VOESE, } 2016 .\end{array}$ \\
\hline & Mulheres e Valores do Trabalho: Estudo em uma Multinacional & $\begin{array}{l}\text { BRANDÃO; FERRAZ; LIMA, } \\
2015 .\end{array}$ \\
\hline & $\begin{array}{l}\text { Mulheres líderes: as desigualdades de gênero, carreira e família nas } \\
\text { organizações de trabalho }\end{array}$ & $\begin{array}{l}\text { CANABARRO; SALVAGNI, } \\
2015 .\end{array}$ \\
\hline & Mulheres, trabalho e administração & $\begin{array}{l}\text { CAPPELLE; MELO; SOUZA, } \\
2013 .\end{array}$ \\
\hline & $\begin{array}{l}\text { Empoderamento de mulheres gerentes: a construção de um modelo teórico } \\
\text { de análise }\end{array}$ & MELO; LOPES, 2012. \\
\hline & A gestão das mulheres em organizações não-governamentais & $\begin{array}{l}\text { FIGUEREDO; } \\
\text { DELLAGNELO, } 2011 .\end{array}$ \\
\hline & $\begin{array}{l}\text { Construção da identidade profissional de mulheres gestoras em empresas de } \\
\text { médio e grande porte }\end{array}$ & $\begin{array}{l}\text { LIMA; LUCAS; FISCHER, } \\
2011 .\end{array}$ \\
\hline & $\begin{array}{l}\text { Da estratégia individual à ação coletiva: grupos de suporte e gênero no } \\
\text { contexto da gestão da diversidade }\end{array}$ & BRUNSTEIN; JAIME, 2009. \\
\hline & $\begin{array}{l}\text { Debatendo diversidade de gênero e raça no contexto organizacional } \\
\text { brasileiro: lei do mercado ou cotas por lei? }\end{array}$ & $\begin{array}{l}\text { COUTINHO; COSTA; } \\
\text { CARVALHO, } 2009 .\end{array}$ \\
\hline & $\begin{array}{l}\text { Diversidade de gênero e formação do endogrupo: uma contribuição da } \\
\text { Teoria da Troca Entre Líder e Membro (LMX) }\end{array}$ & $\begin{array}{l}\text { GODOY; CÉSAR; SILVA; } \\
\text { AMARAL, 2007. }\end{array}$ \\
\hline & $\begin{array}{l}\text { A diversidade de gênero e as diferenças e semelhanças na hierarquia de } \\
\text { valores do trabalho de homens e mulheres no chão de fábrica }\end{array}$ & SILVEIRA, 2006. \\
\hline \multirow{12}{*}{$\begin{array}{l}\frac{\pi}{0} \\
\frac{0}{0} \\
\frac{0}{0} \\
\frac{0}{0} \\
0 \\
\Xi \\
0 \\
0 \\
\tilde{0} \\
0 \\
0 \\
0 \\
0\end{array}$} & $\begin{array}{l}\text { Qual a relação entre diversidade e desempenho? Um estudo sobre a } \\
\text { relação entre a proporção de pessoas com deficiência na produtividade das } \\
\text { empresas brasileiras }\end{array}$ & FERREIRA; RAIS, 2016. \\
\hline & $\begin{array}{l}\text { As práticas de Recursos Humanos para a gestão da diversidade: a inclusão } \\
\text { de deficientes intelectuais em uma Federação Pública do Brasil }\end{array}$ & $\begin{array}{l}\text { MACCALI; KUABARA; } \\
\text { TAKAHASHI; ROGLIO; } \\
\text { BOEHS, } 2015 \text {. }\end{array}$ \\
\hline & Surdo: um estrangeiro em seu país & OLIVEIRA, 2014. \\
\hline & $\begin{array}{l}\text { A gestão de pessoas e o desafio da inclusão das pessoas com deficiência: } \\
\text { uma visão antropológica da deficiência }\end{array}$ & LARA, 2013. \\
\hline & $\begin{array}{l}\text { Incluindo pessoas com deficiência na empresa: estudo de caso de uma } \\
\text { multinacional brasileira }\end{array}$ & $\begin{array}{l}\text { CAMPOS; VASCONCELLOS; } \\
\text { KRUGLIANSKAS, } 2013 .\end{array}$ \\
\hline & $\begin{array}{l}\text { Políticas de gestão de pessoas destinadas aos profissionais com deficiência: } \\
\text { um estudo em uma organização hoteleira da cidade do Rio de Janeiro }\end{array}$ & ARAÚJO; CASTRO, 2013. \\
\hline & $\begin{array}{l}\text { Colocação seletiva de pessoas com deficiência intelectual nas organizações: } \\
\text { um estudo qualitativo }\end{array}$ & $\begin{array}{l}\text { MOURÃO; SAMPAIO; } \\
\text { DUARTE, } 2012 .\end{array}$ \\
\hline & $\begin{array}{l}\text { O tempo como dimensão de pesquisa sobre uma política de diversidade e } \\
\text { relações de trabalho }\end{array}$ & IRIGARAY; VERGARA, 2011. \\
\hline & $\begin{array}{l}\text { Inserção de pessoas com deficiência em organizações brasileiras: um estudo } \\
\text { com empresas socialmente responsáveis }\end{array}$ & FREITAS; MARQUES, 2010. \\
\hline & $\begin{array}{l}\text { Breve análise da legislação das políticas públicas de empregabilidade para } \\
\text { pessoas com deficiência }\end{array}$ & MANHÃES, 2010. \\
\hline & Socialização organizacional de pessoas com deficiência & $\begin{array}{l}\text { CARVALHO-FREITAS; } \\
\text { TOLEDO; NEPOMUCENO; } \\
\text { SUZANO; ALMEIDA, } 2010 .\end{array}$ \\
\hline & $\begin{array}{l}\text { A diversidade através da história: a inserção no trabalho de pessoas com } \\
\text { deficiência }\end{array}$ & FREITAS; MARQUES, 2007. \\
\hline
\end{tabular}




\begin{tabular}{|c|c|c|}
\hline \multirow{4}{*}{ 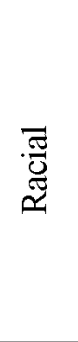 } & $\begin{array}{l}\text { Gestão da diversidade: um estudo de gênero e raça em grandes empresas } \\
\text { brasileiras }\end{array}$ & $\begin{array}{l}\text { GONÇALVES; ESPEJO; } \\
\text { ALTOÉ; VOESE, } 2016 .\end{array}$ \\
\hline & Relações Raciais e Estudos Organizacionais no Brasil & ROSA, 2014. \\
\hline & $\begin{array}{l}\text { Empreendedorismo, cultura e diversidade: a participação dos } \\
\text { empreendedores negros nas atividades empreendedoras no Brasil no } \\
\text { período de } 1990 \text { a } 2008\end{array}$ & $\begin{array}{l}\text { OLIVEIRA; PEREIRA; } \\
\text { SOUZA, } 2013 .\end{array}$ \\
\hline & $\begin{array}{l}\text { Debatendo diversidade de gênero e raça no contexto organizacional } \\
\text { brasileiro: lei do mercado ou cotas por lei? }\end{array}$ & $\begin{array}{l}\text { COUTINHO; COSTA; } \\
\text { CARVALHO, } 2009 .\end{array}$ \\
\hline \multirow{4}{*}{ 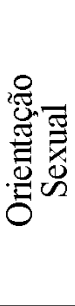 } & $\begin{array}{l}\text { As representações sociais de secretários executivos gays: questões de } \\
\text { gênero e diversidade no trabalho }\end{array}$ & $\begin{array}{l}\text { SOUZA; MARTINS; SOUZA, } \\
2015 .\end{array}$ \\
\hline & $\begin{array}{l}\text { Sentido do trabalho e diversidade: um estudo com homossexuais } \\
\text { masculinos }\end{array}$ & $\begin{array}{l}\text { SILVA; BASTOS; LIMA; } \\
\text { FERRAZ, } 2013 .\end{array}$ \\
\hline & $\begin{array}{l}\text { Políticas de diversidade nas organizações: as relações de trabalho } \\
\text { comentadas por trabalhadores homossexuais }\end{array}$ & $\begin{array}{l}\text { DINIZ; CARRIERI; } \\
\text { GANDRA; BICALHO, } 2013 .\end{array}$ \\
\hline & Diversidade e identidade gay nas organizações & SIQUEIRA; FELLOWS, 2006. \\
\hline & $\begin{array}{l}\text { Transnational Companies and Multiculturalism: Challenges for Analysis } \\
\text { Models in International Management }\end{array}$ & $\begin{array}{l}\text { TEIXEIRA; LIMA; GUEDES; } \\
\text { MACIEL, } 2015 .\end{array}$ \\
\hline \multirow{13}{*}{$\overline{\mathrm{E}}$} & $\begin{array}{l}\text { Mais vale parecê-lo que sê-lo? A impressão, o diálogo e a diversidade para } \\
\text { gestores de inovação }\end{array}$ & MARTINEZ, 2016. \\
\hline & $\begin{array}{l}\text { Tatuagens, Piercings e Diversidade Cultural: o Que Gestores Dizem Sobre } \\
\text { Esse Tema? }\end{array}$ & $\begin{array}{l}\text { BARBOSA; BRITO; } \\
\text { BIZARRIA, } 2016 .\end{array}$ \\
\hline & $\begin{array}{l}\text { Contexto, políticas públicas e práticas empresariais no tratamento da } \\
\text { diversidade no Brasil }\end{array}$ & FREITAS, 2015. \\
\hline & $\begin{array}{l}\text { Intencionalidade incorporada: intersecção entre a diversidade e os estudos } \\
\text { das práticas organizacionais }\end{array}$ & FIGUEIREDO, 2015. \\
\hline & $\begin{array}{l}\text { Atitudes de aceitação e rejeição de indivíduos às ações organizacionais em } \\
\text { prol da diversidade da força de trabalho }\end{array}$ & $\begin{array}{l}\text { FERNANDES; LOPES; } \\
\text { OLIVEIRA; FERREIRA; } \\
\text { WELZEL; PEREIRA, } 2014 .\end{array}$ \\
\hline & $\begin{array}{l}\text { Amplitude da gestão da(s) diversidade(s) - implicações organizacionais e } \\
\text { sociais }\end{array}$ & PINHEIRO; GOIS, 2013. \\
\hline & $\begin{array}{l}\text { Inclusão do tema Gestão da(s) Diversidade(s) nos currículos dos cursos de } \\
\text { administração: um estudo exploratório na UFRRJ }\end{array}$ & PINHEIRO; GOIS, 2012. \\
\hline & Gestão da diversidade e a intenção de compra do consumidor & $\begin{array}{l}\text { PEREIRA; LIMA; ORTIZ; } \\
\text { SILVA; SILVA; ROSIANO, } \\
2012 .\end{array}$ \\
\hline & $\begin{array}{l}\text { Leituras do discurso formal de gerentes de projetos a respeito da } \\
\text { diversidade em equipes }\end{array}$ & ROCHA-PINTO; DIAS, 2012. \\
\hline & Gestão das diferenças humanas nos espaços organizacionais & PEREIRA, 2011. \\
\hline & Ser ou não ser favorável às práticas de diversidade? Eis a questão & $\begin{array}{l}\text { PEREIRA; HANASHIRO, } \\
2010 .\end{array}$ \\
\hline & $\begin{array}{l}\text { Gestão da diversidade: uma gestão necessária para estimular a inovação e } \\
\text { aumentar a competitividade das empresas de Contabilidade e Auditoria }\end{array}$ & $\begin{array}{l}\text { CARDOSO; FARIAS } \\
\text { FILHO; CARDOSO; DEIRO; } \\
\text { OLIVEIRA, } 2007 . \\
\end{array}$ \\
\hline & $\begin{array}{l}\text { Política pública e diversidade: reflexões a partir do pensamento pós- } \\
\text { moderno }\end{array}$ & CAMPOS; COSTA, 2006. \\
\hline
\end{tabular}

Fonte: Organizada pelos autores, segundo dados da pesquisa, 2017.

De forma a ilustrar os tópicos mais abordados nas pesquisas sobre a gestão da diversidade, elaborou-se a nuvem de palavra reproduzida abaixo, considerando as palavras-chave presentes em cada um dos artigos selecionados. 
Figura 1- Nuvem de Palavras Gestão da Diversidade

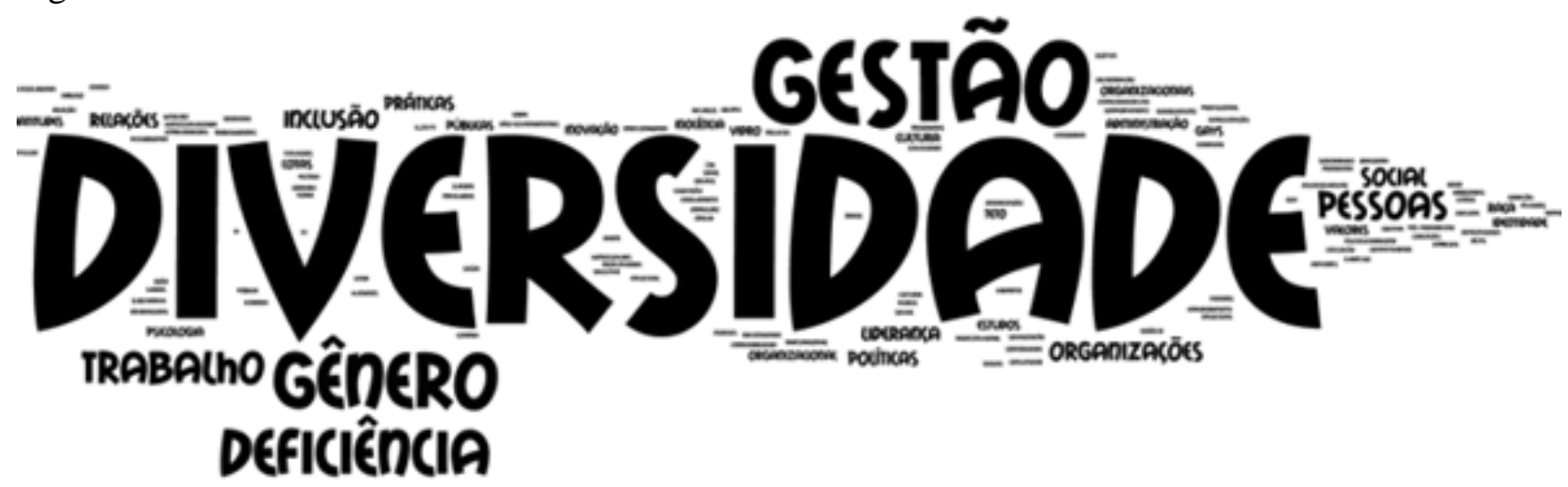

Fonte: Organizada pelos autores, segundo dados da pesquisa, 2017.

Como esperado, os termos "Gestão" e "Diversidade" tiveram destaque na nuvem de palavras. Outra confirmação foi à expressividade de termos relacionados ao eixo gênero e pessoas com deficiência. A nuvem de palavras, em linhas gerais, ratificou e representou graficamente a situação identificada na distribuição dos artigos nos eixos da diversidade de Pinheiro \& Gois (2013).

Evidencia-se, com a identificação e distribuição dos artigos nos eixos da diversidade e a consequente constatação de que há dimensões da diversidade nas organizações ainda pouco estudadas, que há um campo de pesquisa profícuo aberto aos pesquisadores da administração, uma verdadeira "terra virgem" a ser desbravada por aqueles que pretendam compreender mais profundamente a gestão da diversidade no Brasil.

\section{CONSIDERAÇÕES FINAIS}

O objetivo geral deste trabalho foi analisar os artigos publicados sobre gestão da diversidade no período de 2006 a 2016, disponibilizados na base de dados Spell. Para a consecução deste objetivo, realizou-se pesquisa descritiva com vistas a caracterizar demograficamente o conjunto de artigos selecionados.

Os artigos foram avaliados e as informações necessárias tabuladas na perspectiva de obter as seguintes informações, tomadas como categorias de análise: 1) conhecer a distribuição dos artigos sobre gestão da diversidade no período 2006-2016;2) identificar o padrão de autoria e os pesquisadores com mais publicações; 3 ) mensurar a quantidade de artigos publicados por periódico, e apresentar a distribuição dos artigos nos estratos de classificação do Qualis CAPES; 4) indicar os centros institucionais e geográficos difusores da discussão sobre gestão da diversidade; e 5) apresentar os eixos da diversidade mais recorrentes nos trabalhos selecionados.

Atendo-se aos objetivos específicos, os resultados da pesquisa demonstram que:

1) não há constância nas publicações sobre gestão da diversidade de 2006 a 2016. Há, sim, oscilação no número de artigos por ano no período analisado, o que impossibilitou a identificação de uma tendência ou projeção a respeito da produção sobre a temática;

2) evidenciou-se que número considerável dos artigos são produzidos por dois ou mais autores, a confirmar a tendência de parceria já identificada em outros estudos na área de administração. Em relação à produtividade, o destaque foi à professora Jamille Barbosa Cavalcanti Pereira, associada à Universidade Presbiteriana Mackenzie, com quatro artigos publicados no período; 
3) há uma pulverização dos artigos em diversos periódicos. A média calculada é de 1,29 artigos por periódico - 44 artigos publicados em 34 periódicos distintos. A situação deve ser avaliada na perspectiva da constituição de um veículo próprio para divulgação dos trabalhos realizados. Quem sabe assim não ocorra maior estímulo à produção científica e a adesão de novos pesquisadores a discussão;

4) $77 \%$ dos artigos foram publicados em periódicos classificados pela Capes como Qualis B, em especial B2. É preciso ressaltar também que um número significativo de artigos foi publicado em periódicos Qualis A2, o que sinaliza a qualidade dos trabalhos realizados;

5) os estados do Sudeste e Sul do país, e consequentemente as instituições localizadas nestes estados, constituem os centros difusores da pesquisa sobre gestão da diversidade. Deriva deste quadro a necessidade de intercâmbio entre pesquisadores e o fortalecimento de redes de cooperação que promovam a inserção de pesquisadores que atuam nas regiões Norte, Nordeste e Centro-Oeste, por meio, por exemplo, da constituição de grupos de pesquisa interregionais que tratem prioritariamente da gestão da diversidade;

6) há uma desigual distribuição dos artigos quando se considera os eixos da diversidade. As dimensões gênero e pessoas com deficiência apresentaram maior número de artigos. A questão racial e a dimensão da orientação sexual também tiveram representatividade nos trabalhos avaliados, mesmo que expressivamente menor que as duas dimensões anteriores. A ausência se deu na discussão sobre os eixos geracional e imigracional, o que denota que a gestão da diversidade no Brasil ainda é um campo aberto, uma "terra virgem”, a espera de pesquisadores que se dediquem a desbravá-la.

Por se tratar de uma pesquisa circunscrita aos artigos publicados na base Spell no período de 2006 a 2016, este trabalho acaba por não considerar outros importantes veículos de divulgação da produção científica. O primeiro deles, os anais de eventos científicos. Na área de Administração, destacam-se os eventos promovidos pela ANPAD, e dentre eles, o Encontro de Estudos Organizacionais - EnEO. Este evento foi particularmente citado porque apresenta, como um de seus temas de interesse, Gênero e Diversidade. Uma segunda fonte a considerar para composição do estado da arte sobre gestão da diversidade são as dissertações e teses produzidas nos programas de pós-graduação em Administração e áreas afins. A literatura internacional, sobretudo aquela publicada em periódicos de alto impacto, também deve ser acrescentada a lista de fontes para elaboração de retrato mais fidedigno da gestão da diversidade no Brasil, seja por meio de estudos comparativos ou a partir da utilização de teorias e metodologias elaboradas em países como Estados Unidos e Canadá, expoentes da discussão sobre diversidade.

Além da limitação indicada no parágrafo anterior, é preciso destacar outra, que se refere ao uso do termo "Gestão da Diversidade" para levantamento dos artigos na base Spell. É provável que com a pesquisa circunscrita ao termo indicado, pode-se não ter localizado um ou outro estudo disponível na Spell. Em pesquisas futuras pretende-se superar esse problema com a pesquisa de artigos sobre a diversidade organizacional por meio da combinação de termos, a exemplo dos que denominam os seis eixos da diversidade adotados neste estudo.

Outro aspecto a ressaltar foi à opção por uma análise demográfica das publicações sobre gestão da diversidade. Priorizou-se a análise de determinadas características, mais de caráter quantitativo, em detrimento da avaliação qualitativa dos artigos. Em próxima pesquisa, pretende-se analisar as publicações de forma a apreender os objetivos, metodologia, resultados, identificar os autores mais citados, as redes de autores, dentre outros elementos possíveis quando se realiza um estudo de cunho prioritariamente qualitativo. 
Dessa forma, sugere-se para futuras pesquisas o levantamento e análise bibliométrica das publicações sobre gestão da diversidade nos eventos promovidos pela ANPAD, em especial o EnEO; o mapeamento e avaliação quantitativa e qualitativa das dissertações e teses dos programas de mestrado e doutorado em Administração que tratem da gestão da diversidade; o recenseamento em múltiplas bases de dados de artigos de uma dimensão ou eixo específico da diversidade; e a realização de estudos comparativos com trabalhos publicados em periódicos internacionais.

\section{REFERÊNCIAS}

ALVES, M. A.; GALEÃO-SILVA, L. G. A crítica da gestão da diversidade nas organizações. Revista de Administração de Empresas, São Paulo, v. 44, n. 3, p. 20-29, 2004.

ARAÚJO, M. P. F.; CASTRO, C. L. C. Políticas de gestão de pessoas destinadas aos profissionais com deficiência: um estudo em uma organização hoteleira da cidade do Rio de Janeiro. TurismoVisão e Ação, Balneário Camboriú, SC, v. 15, n. 2, p. 262-262, 2013.

ARAÚJO, P. P. A gestão da diversidade enquanto motor de um processo de mudança cultural. 2012. Dissertação (Mestrado em Economia e Gestão de Recursos Humanos)- Faculdade de Economia, Universidade do Porto, Portugal, 2012.

BARBOSA, F. L. S.; BRITO, A. D. S.; BIZARRIA, F. P. A. Tatuagens, piercings e diversidade cultural: o que gestores dizem sobre esse tema? Teoria e Prática em Administração, João Pessoa, PB, v. 6, n. 2, p. 78-106, 2016.

BRANDÃO, R. A.; FERRAZ, S. B.; LIMA, T. C. B. Mulheres e Valores do Trabalho: Estudo em uma Multinacional. Revista Organizações em Contexto, São Paulo, v. 11, n. 22, p. 487-514, 2015.

BRUNSTEIN, J.; JAIME, P. Da estratégia individual à ação coletiva: grupos de suporte e gênero no contexto da gestão da diversidade. RAE-eletrônica, São Paulo, v. 8, n. 2, art. 4, p. 1-33, 2009.

CAMPOS, A. M. S. M.; COSTA, I. S. A. Política pública e diversidade: reflexões a partir do pensamento pós-moderno. Revista Gestão \& Tecnologia, Pedro Leopoldo, MG, v. 6, n. 2, p. 1-12, 2006.

CAMPOS, J. G. F.; VASCONCELLOS, E. P. G.; KRUGLIANSKAS, G. Incluindo pessoas com deficiência na empresa: estudo de caso de uma multinacional brasileira. Revista de Administração, Frederico Westphalen, RS, v. 48, n. 3, p. 560-573, 2013.

CANABARRO, J. R. D. S.; SALVAGNI, J. Mulheres líderes: as desigualdades de gênero, carreira e família nas organizações de trabalho. Revista de Gestão e Secretariado, São Paulo, v. 6, n. 2, p. 88-110, 2015.

CAPPELLE, M. C. A.; MELO, M. C. O. L.; SOUZA, N. L. Mulheres, trabalho e administração.

Revista Interdisciplinar de Gestão Social, Salvador, BA, v. 2, n. 2, p. 161-191, 2013. 
CARDOSO, J. A. S.; FARIAS FILHO, J. R.; CARDOSO, M. M. S.; DEIRO, R.; OLIVEIRA, U. Gestão da diversidade: uma gestão necessária para estimular a inovação e aumentar a competitividade das empresas de Contabilidade e Auditoria. Pensar Contábil, Rio de Janeiro, v. 9, n. 36, p. 1-12, 2007.

CARVALHO-FREITAS, M. N.; TOLEDO, I. D.; NEPOMUCENO, M. F.; SUZANO, J. C. C.; ALMEIDA, L. A. D. Socialização organizacional de pessoas com deficiência. Revista de Administração de Empresas, São Paulo, v. 50, n. 3, p. 264-275, 2010.

COSTA, L. F.; GOMES, J. O. Editorial: - Cinco anos do lançamento do Spell - Scientific Periodicals Electronic Library e da Indexação da Revista Perspectivas em Gestão \& Conhecimento neste Portal. Perspectivas em Gestão \& Conhecimento, João Pessoa, PB, v. 7, n. 1, p. 1-4, 2017.

COSTA, S.; FERREIRA, C. Diversidade e minorias nos estudos organizacionais brasileiros: presença e lacunas na última década. In: ENCONTRO DE ESTUDOS ORGANIZACIONAIS, 4, 2006, Porto Alegre, Anais [...]. Porto Alegre: ANPAD, 2006.

COUTINHO, L. R. S.; COSTA, A. M.; CARVALHO, J. L. F. D. S. Debatendo diversidade de gênero e raça no contexto organizacional brasileiro: lei do mercado ou cotas por lei? Sociedade, Contabilidade e Gestão, Rio de Janeiro, v. 4, n. 1, p. 21-37, 2009.

CRESWELL, J. W. Projeto de pesquisa métodos qualitativo, quantitativo e misto. In: Projeto de pesquisa métodos qualitativo, quantitativo e misto. Tradução Magda Lopes. 3.ed. Porto Alegre: Artmed, 2010.

DINIZ, A. P. R.; CARRIERI, A. P.; GANDRA, G.; BICALHO, R. A. Políticas de diversidade nas organizações: as relações de trabalho comentadas por trabalhadores homossexuais. Revista Economia \& Gestão, Belo Horizonte, MG, v. 13, n. 31, p. 93-114, 2013.

FERNANDES, F. R.; LOPES, F. M.; OLIVEIRA, G. A.; FERREIRA, T. S.; WELZEL, E.; PEREIRA, J. B. C. Atitudes de aceitação e rejeição de indivíduos às ações organizacionais em prol da diversidade da força de trabalho. Revista Gestão Organizacional, Chapecó, SC, v. 7, n. 1, p. 19-29, 2014.

FERREIRA, L. C. M.; RAIS, L. A. Qual a relação entre diversidade e desempenho? Um estudo sobre a relação entre a proporção de pessoas com deficiência na produtividade das empresas brasileiras. Revista Brasileira de Gestão de Negócios, São Paulo, v. 18, n. 59, p. 108-124, 2016.

FIGUEIREDO, M. D. Intencionalidade incorporada: intersecção entre a diversidade e os estudos das práticas organizacionais. Gestão \& Conexões, Vitória, ES, v. 4, n. 1, p. 20-44, 2015.

FIGUEREDO, P. M.; DELLAGNELO, E. H. L. A gestão das mulheres em organizações não-governamentais. Revista Pensamento Contemporâneo em Administração, Rio de Janeiro, v. 5, n. 2, p. $1-16,2011$. 
FLEURY, M. T. L. Gerenciando a diversidade cultural: experiências de empresas brasileiras. Revista de Administração de Empresas, São Paulo, v. 40, n. 3, p. 18-25, 2000.

FREITAS, M. E. Contexto, políticas públicas e práticas empresariais no tratamento da diversidade no Brasil. Revista Interdisciplinar de Gestão Social, Salvador, BA, v. 4, n. 3, p. 87-135, 2015.

FREITAS, M. N. C.; MARQUES, A. L. A diversidade através da história: a inserção no trabalho de pessoas com deficiência. Organizações \& Sociedade, Salvador, BA, v. 14, n. 41, p. 59-78, 2007.

; __ . Inserção de pessoas com deficiência em organizações brasileiras: um estudo com empresas socialmente responsáveis. GESTÃ O.Org - Revista Eletrônica de Gestão Organizacional, Recife, PE, v. 8, n. 3, p. 483-502, 2010.

GODOY, A. S.; CÉSAR, A. M. R. V. C.; SILVA, A. A.; AMARAL, D. J. Diversidade de gênero e formação do endogrupo: uma contribuição da Teoria da Troca Entre Líder e Membro (LMX). Revista Brasileira de Gestão de Negócios, São Paulo, v. 9, n. 24, p. 41-59, 2007.

GOMES, G.; LAVARDA, C. E. F.; TORRENS, E. W. Revisão da literatura sobre orçamento em cinco periódicos internacionais nos anos de 2000 até 2009. Revista de Gestão, São Paulo, v. 19, n. 2, p. 107-123, 2012.

GOMES, G.; MACHADO, D. D. P.; SCARPIN, M. R. S. Produção científica de cultura organizacional sob a ótica das redes sociais no período de 2006-2010: análise nos periódicos de alto impacto brasileiros. RACE-Revista de Administração, Contabilidade e Economia, Joaçaba, SC, v. 13, n. 2, p. 453-478, 2014.

GONÇALVES, E. B. P.; ESPEJO, M. M. D. S. B.; ALTOÉ, S. M. L.; VOESE, S. B. Gestão da diversidade: um estudo de gênero e raça em grandes empresas brasileiras. Enfoque Reflexão Contábil, Maringá, PR, v. 35, n. 1, p. 95-112, 2016.

GORDONO, F. S. Conceitos, práticas e estudo de casos da gestão da diversidade em empresas do centro oeste paulista. 2009. Dissertação (Mestrado em Engenharia de Produção) - Universidade Estadual Paulista Júlio de Mesquita Filho, Bauru, São Paulo, 2009.

HENDERSON, P. A.; FERREIRA, M. A. A.; DUTRA, J. S. As barreiras para a ascensão da mulher a posições hierárquicas: um estudo sob a óptica da gestão da diversidade no Brasil. Revista de Administração da UFSM, Santa Maria, RS, v. 9, n. 3, p. 489-505, 2016.

IRIGARAY, H. A. R.; VERGARA, S. C. O tempo como dimensão de pesquisa sobre uma política de diversidade e relações de trabalho. Cadernos EBAPE.BR, Rio de Janeiro, v. 9, n. 4, art. 8, p. 1085-1098, 2011. 
JABBOUR, C. J. C.; GORDONO, F. S.; OLIVEIRA, J. H. C.; MARTINEZ, J. C.; BATTISTELLE, R. A. G. Diversity management: challenges, benefits, and the role of human resource management in Brazilian organizations. Equality, Diversity and Inclusion: An International Journal, v. 30, n. 1, p. 58-74, 2011.

LARA, L. F. A gestão de pessoas e o desafio da inclusão das pessoas com deficiência: uma visão antropológica da deficiência. Revista Capital Científico - Eletrônica, Guarapuava, PR, v. 11, n. 3, p. 121-142, 2013.

LIMA, L. C.; LUCAS, A. C.; FISCHER, A. L. Construção da identidade profissional de mulheres gestoras em empresas de médio e grande porte. Pensamento \& Realidade, São Paulo, v.26, n. 2, p. 3-21, 2011.

MACCALI, N.; KUABARA, P. S. S.; TAKAHASHI, A. R. W.; ROGLIO, K. D.; BOEHS, S. T. M. As práticas de Recursos Humanos para a gestão da diversidade: a inclusão de deficientes intelectuais em uma Federação Pública do Brasil. Revista de Administração Mackenzie, São Paulo, v. 16, n. 2, p. 157-187, 2015.

MANHÃES, V. S. Breve análise da legislação das políticas públicas de empregabilidade para pessoas com deficiência. Cadernos Gestão Pública e Cidadania, São Paulo, v. 15, n. 57, art. 16, p. 254-262, 2010.

MARTINEZ, V. P. R. Mais Vale Parecê-lo que Sê-lo? A Impressão, o Diálogo e a Diversidade para Gestores de Inovação. Gestão \& Regionalidade, São Caetano do Sul, SP, v. 32, n. 96, p. 135-150, 2016.

MELO, M. C. O. L.; LOPES, A. L. M. Empoderamento de mulheres gerentes: a construção de um modelo teórico de análise. Revista Gestão \& Planejamento, Salvador, BA, v. 13, n. 3, p. 0-0, 2012.

MOURÃO, L.; SAMPAIO, S.; DUARTE, M. H. Colocação seletiva de pessoas com deficiência intelectual nas organizações: um estudo qualitativo. Organizações \& Sociedade, Salvador, BA, v. 19, n. 61, p. 209-229, 2012.

OLIVEIRA, J. S.; PEREIRA, J. A.; SOUZA, M. C. D. Empreendedorismo, cultura e diversidade: a participação dos empreendedores negros nas atividades empreendedoras no Brasil no período de 1990 a 2008. Contextus - Revista Contemporânea de Economia e Gestão, Fortaleza, CE, v. 11, n. 2, p. 7-30, 2013.

OLIVEIRA, S. R. N. Surdo: um estrangeiro em seu país. Revista Interdisciplinar de Gestão Social, Salvador, BA, v. 3, n. 2, p. 204-221, 2014.

PEREIRA, J. B. C. Gestão das diferenças humanas nos espaços organizacionais. Revista de Carreiras e Pessoas, São Paulo, v. 1, n. 2, p. 81-100, 2011. 
PEREIRA, J. B. C.; HANASHIRO, D. M. M. Ser ou não ser favorável às práticas de diversidade? Eis a questão. Revista de Administração Contemporânea, Maringá, PR, v. 14, n. 4, art. 6, p. 670683, 2010.

PEREIRA, J. C.; LIMA, E. M. C.; ORTIZ, M. R. C.; SILVA, T. A.; SILVA, T. N.; ROSIANO, Y. P. A. Gestão da diversidade e a intenção de compra do consumidor. Revista de Administração da Unimep, Piracicaba, SP, v. 10, n. 2, p. 81-100, 2012.

PINHEIRO, J. L. A.; GOIS, J. B. H. Inclusão do tema Gestão da(s) Diversidade(s) nos currículos dos cursos de administração: um estudo exploratório na UFRRJ. Revista de Carreiras e Pessoas, São Paulo, v. 2, n. 3, p. 84-98, 2012.

Amplitude da gestão da(s) diversidade(s) - implicações organizacionais e sociais.

Revista de Carreiras e Pessoas, São Paulo, v. 3, n. 2, p. 72-90, 2013.

ROCHA-PINTO, S. R.; DIAS, P. D. G. Leituras do discurso formal de gerentes de projetos a respeito da diversidade em equipes. Revista de Gestão e Projetos, São Paulo, v. 3, n. 1, p. 197-224, 2012.

ROSA, A. R. Relações Raciais e Estudos Organizacionais no Brasil. Revista de Administração Contemporânea, Maringá, PR, v. 18, n. 3, p. 240-260, 2014.

SILVA, A.; BASTOS, G. M. F.; LIMA, T. C. B.; FERRAZ, S. F. S.; CABRAL, A. C. A. Sentido do trabalho e diversidade: um estudo com homossexuais masculinos. Revista ADM.MADE, Rio de Janeiro, v. 17, n. 2, p. 85-105, 2013.

SILVEIRA, N.A diversidade de gênero e as diferenças e semelhanças na hierarquia de valores do trabalho de homens e mulheres no chão de fábrica. Revista de Gestão, São Paulo, v. 13, n. especial, p. 77-91, 2006.

SIQUEIRA, M.; FELLOWS, A. Z. Diversidade e identidade gay nas organizações. GESTÃo.Org Revista Eletrônica de Gestão Organizacional, Recife, PE, v. 4, n. 3, p. 69-81, 2006.

SOUZA, E. C. P.; MARTINS, C. B.; SOUZA, R. B. As representações sociais de secretários executivos gays: questões de gênero e diversidade no trabalho. Gestão \& Conexões, Vitória, ES, v. 4, n. 1, p. 116-139, 2015.

TEIXEIRA, A. C. C.; LIMA, D. M. C.; GUEDES, A. L. M.; MACIEL, E. Transnational Companies and Multiculturalism: Challenges for Analysis Models in International Management. Revista Pensamento Contemporâneo em Administração, Niterói, RJ, v. 9, n. 2, p. 84-95, 2015.

THOMAS, D. A.; ELY, R. J. Making differences matter: a new paradigm for managing diversity. Harvard Business Review, Massachusetts, EUA, v. 74, n. 5, p. 79-91, 1996. 